\title{
PUPUNHA NO MERCADO DE MANAUS: PREFERÊNCIAS DE CONSUMIDORES E SUAS IMPLICAÇÕES ${ }^{1}$
}

\author{
CHARLES R. CLEMENT ${ }^{2} \&$ LENOIR A. SANTOS 3
}

\begin{abstract}
RESUMO - A demanda para o fruto fresco de pupunha (Bactris gasipaes Kunth, Palmae) permanece estável após 50 anos de pesquisa e fomento na Amazônia. Entrevistas com 30 consumidores na principal feira de Manaus, durante a segunda safra, determinaram que o fruto preferido é o vermelho (por 53\%), de tamanho médio (67\%), moderadamente a oleoso (53\% oleoso e $40 \%$ moderadamente), em cachos grandes (50\%) e com um custo razoável (R \$5/cacho em outubro 2001), diferente dos frutos usados no fomento (grandes, secos, mais caros) e de dificil criação por melhoristas. A quantificação e o detalhamento destas preferências são essenciais para reorientar a pesquisa e o fomento.
\end{abstract}

Termos para indexação: fruto fresco, aparência, cor, textura, preço.

\section{PEACH PALM IN MANAUS, MARKET AMAZONAS, BRAZIL: CONSUMER PREFERENCES AND THEIR IMPLICATIONS}

\begin{abstract}
The demand for fresh fruit of peach palm (Bactris gasipaes Kunth) has remained stable through 50 years of research and promotion in the Brazilian Amazon. Interviews with 30 consumers at the principal market in Manaus, Amazonas, during the second harvest determined that red (by $53 \%$ ), medium weight (67\%), moderately oily fruit (53\% oily and $40 \%$ moderately oily), in large bunches (50\%) with a reasonable price (R $\$ 5=\mathrm{US} \$ 2$ / bunch in October 2001) is preferred, which is different from the fruit used in promotion (large, dry, higher price) and difficult for breeders to create. Quantifying and detailing these preferences are essential to guide future research and promotion.
\end{abstract}

Index terms: fresh fruit, appearance, color, texture, price.

A pupunha (Bactris gasipaes Kunth, Palmae) foi domestica$\mathrm{da}^{4}$ para que seu fruto fosse usado na economia indígena nas formas de farinha, bebida fermentada e fruto cozido. Na economia atual, tanto urbana como rural, é usado como fruto cozido e é subutilizado (Clement, 2000). A demanda para fruto fresco (usado após cozido) manteve-se estável ao longo das últimas décadas, apesar de uma campanha de fomento à produção bem executada. Uma parte dessa campanha usou germoplasma de população de Fonte Boa (Amazonas), da raça mesocarpa 'Solimões', pois acreditava-se empiricamente que este germoplasma atenderia à demanda para fruto fresco em Manaus (Moreira Gomes et al., 1987), o maior mercado para pupunha no Estado do Amazonas. No entanto, os municípios do baixo Rio Solimões e alto Rio Amazonas, onde este germoplasma foi plantado, não são importantes fornecedores de pupunha para Manaus, hoje. Uma conseqüência de uma campanha de fomento que aumentou a oferta, mas não a demanda, é que os produtores perderam tempo e dinheiro, o que sugere falhas no plano de fomento e na pesquisa em que se baseava.

Cachos de pupunha do município de Fonte Boa obtinham os maiores preços na feira principal de Manaus, mesmo após os maus tratos de uma viagem de $1011 \mathrm{~km}$ no porão de um barco de linha. No entanto, as preferências dos consumidores não foram analisadas na época. $\mathrm{O}$ objetivo do presente estudo preliminar foi determinar algumas características dos frutos e cachos de pupunha que a população de Manaus acredita serem importantes, em preparação para um estudo mais detalhado, bem como avaliar as implicações destas preferências.

$\mathrm{Na}$ entressafra, no período do início de setembro ao final de outubro de 2001, foram entrevistadas 30 pessoas que compraram pupunha na Feira da Banana, o principal ponto de entrada e comercialização de pupunha no centro de Manaus. Procurou-se obter informações sobre as preferências para: cor do fruto (indiferente, amarela, alaranjada e vermelha); tamanho do fruto e do cacho (pequeno, médio e grande); textura do fruto (oleosa, mais oleosa que seca, meia:meia, mais seca que oleosa e seca); aparência do fruto (indiferente, casca lisa ou rachada $^{5}$; presença de danos por insetos na casca do fruto (não importa ou importa); como escolher qual cacho comprar (só olhando, apertando, descascando, abrindo ou amassando ${ }^{6}$ a polpa); preço pago pelo cacho
( $\mathrm{R} \$ 1,00=\mathrm{US} \$ 0,38$ ); forma de consumo pretendido (só cozido, farinha ou outro). Observou-se o movimento da feira e obtiveram-se informações preliminares sobre a cadeia de comercialização centrada em Manaus.

Cachos de pupunha chegam diariamente à Feira da Banana vindos principalmente pelo Rio Solimões, especialmente de Coari (368 $\mathrm{km}$ via fluvial de Manaus), Tefé (663 km), Fonte Boa (1011 km) e Tabatinga $(1650 \mathrm{~km})$. A maior chegada de pupunha ocorreu nas $3^{\text {as }}$ às $6^{\text {as }}$ feiras. Os feirantes sabem que a distância até Manaus é positivamente correlacionada ao tamanho dos frutos ao longo do rio, o que permite verificar a informação do gerente do barco sobre sua origem. Barcos de linha geralmente trazem centenas de cachos, podendo trazer até 2.000 cachos num só lote. Os cachos geralmente são vendidos por R \$3-4 nos cais do porto, embora cachos especialmente grandes e bonitos podem comandar preços de até R\$8-9. Dependendo da quantidade e da aparência dos frutos, um lote leva de 3 a 7 dias para ser vendido.

$\mathrm{Na}$ Feira da Banana, uma controla a maioria absoluta da comercialização da pupunha que chega durante a safra menor, ocupando um espaço de 3 x 9 m cedida pela Prefeitura, onde espalha ou empilha os cachos diretamente no chão de cimento. A recomendação técnica é pendurar os cachos para melhor ventilação, o que maximiza a vida de prateleira (Mora Urpí et al., 1997). Durante uma manhã, em média, 50 pessoas passam por hora ao lado da área comercial, das quais metade olha e/ou examina os cachos, e sete realizam uma compra.

Mais de $50 \%$ acredita que frutos de cor vermelha são melhores (Figura 1A). A cor vermelha tende a ser altamente correlacionada à quantidade de coroteno na polpa (Mora Urpí et al., 1997), mesmo que sejam pigmentos distintos (antocianina vs caroteno).

A maioria dos compradores preferem frutos médios a grandes, em cachos grandes a médios (Figura 1B e C), e ao mesmo tempo preferem frutos algo oleosos (Figura 1D). Estas duas demandas são difíceis de atender, pois enquanto existe uma correlação alta e positiva entre tamanho e amido (ou seja, frutos secos), a correlação é alta e negativa entre amido e óleo (Clement et al., 1998), e,conseqüentemente entre tamanho e óleo. O resultado é que muitos acabam comprando cachos que não são de sua preferência (Figura 1E).

Setenta por cento dos compradores preferiram os frutos lisos e

1 (Trabalho 020/2002). Recebido: 25/01/2002. Aceito para publicação: 28/08/2002.

2 Pesquisador Titular, Instituto Nacional de Pesquisas da Amazônia - INPA, Cx. Postal 478, 69011-970 Manaus, AM, Brasil. (55-92) 643-1862 cclement@inpa.gov.br Bolsista do CNPq.

3 Eng. Agr., Instituto Nacional de Pesquisas da Amazônia - INPA, Cx. Postal 478, 69011-970 Manaus, AM, Brasil. (55-92) 643-1862 1santos@inpa.gov.br

4 Selecionada e propagada em sistemas agrícolas tradicionais até houve mudanças nos genótipos e fenótipos que fizeram a população mais útil aos humanos que praticavam a domesticação. Veja Clement (1999) para maiores detalhes.

5 Casca rachada é considerada fator de qualidade em Costa Rica (Clement, 1986).

6 Amassar a polpa permite estimar a sua quantidade de óleo (Clement e Arkcoll, 1991). 
brilhantes, pois acreditam que têm boa qualidade da polpa (no caso polpa mais ou menos oleosa), mas não detalharam esta idéia; apenas $20 \%$ dos compradores manipularam os frutos para sentir a qualidade da polpa (Figura 1F). Apenas um comprador amassou a polpa entre os dedos. A maioria dos compradores (63\%) não quis aceitar frutos com danos de insetos ou outras manchas, mas, na prática, teve que aceitálos, porque é muito raro encontrar um cacho tão limpo como o desejado.

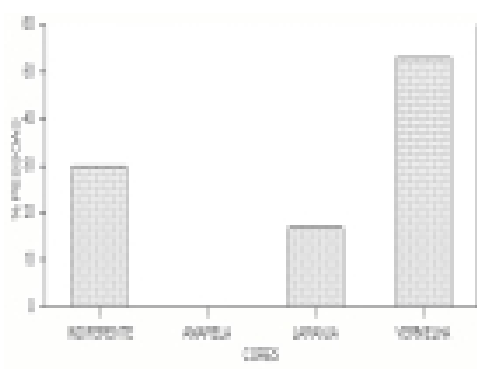

$1 \mathbf{A}$

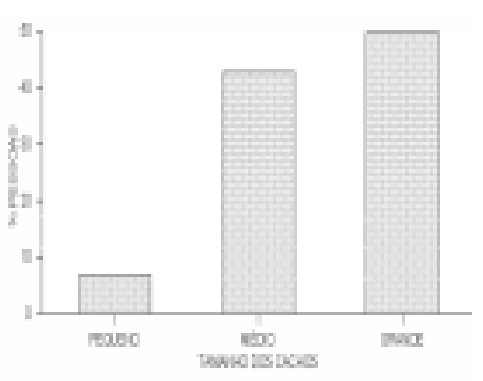

$1 \mathbf{C}$

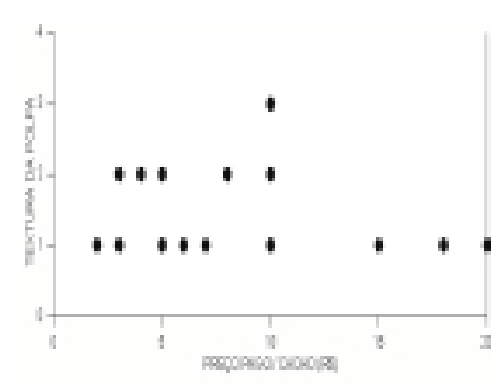

$1 \mathbf{E}$

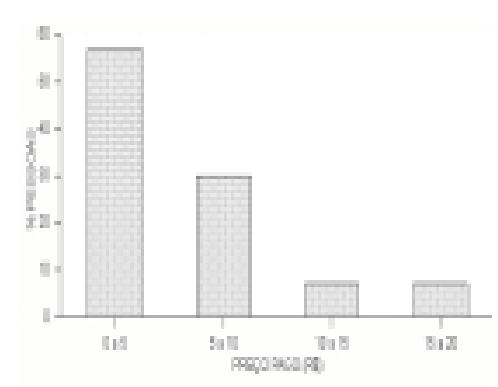

$1 \mathrm{G}$

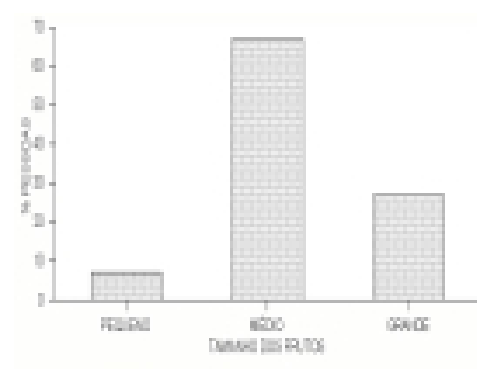

$1 \mathbf{B}$

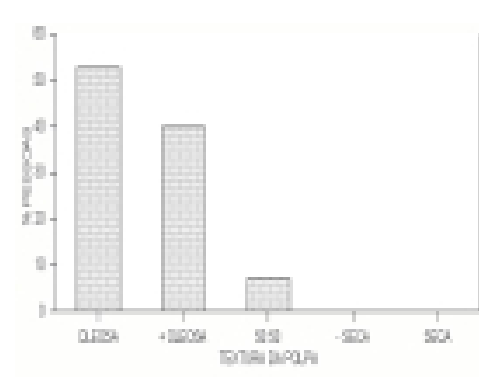

$1 \mathrm{D}$

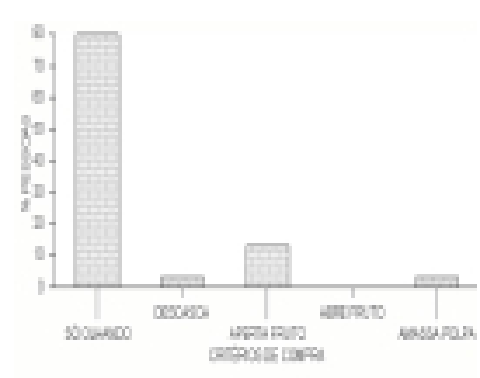

$1 \mathbf{F}$

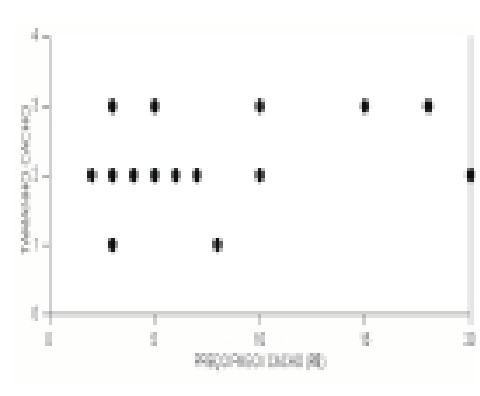

$1 \mathbf{H}$
FIGURA 1 - Algumas preferências dos compradores e dos frutos e cachos de pupunha observados no mercado de Manaus (Amazonas, Brasil), em setembro e outubro de 2001. A. Preferência para cor do fruto. B. Preferência por tamanho do fruto. C. Preferência por tamanho do cacho. D. Preferência por textura da polpa do fruto. E. Relação entre preferência por textura e preço efetivamente pago / cacho. F. Práticas de escolha dos cachos. G. Freqüência de pessoas pagando por cachos de diferentes intervalos de valor. H. Relação entre preferência por tamanho e preço pago / cacho.
Os 30 compradores entrevistados pagaram em média $\mathrm{R} \$ 7,10$ (desvio-padrão $\pm 4,60$ ) por cacho. Um comprador pagou $\mathrm{R} \$ 20$ por um cacho grande e outros 3 pagaram de $\mathrm{R} \$ 15$ a $\mathrm{R} \$ 18$ por cachos maiores; todos estes cachos foram de Fonte Boa (Amazonas), confirmando assim a informação empírica de Moreira Gomes et al. (1987). A maioria dos compradores $(57 \%)$, no entanto, preferiu pagar $\mathrm{R} \$ 5$ ou menos por cacho (Figura $1 \mathrm{G}$ ); os compradores neste grupo pagaram $\mathrm{R} \$ 4,10( \pm 1,10)$ por seu cacho. Mais uma vez ocorreu uma discrepância entre preferência e prática: o grupo que pagou $\mathrm{R} \$ 5$ / cacho incluiu indivíduos que preferiam cachos grandes, mas ficaram com cachos pequenos (Figura 1H).

Em resumo, a maioria dos 30 compradores de pupunha entrevistados nesta feira de Manaus preferia frutos médios, oleosos e vermelhos com preço razoável, embora houvesse um segundo grupo que aceitou pagar mais, mas com as mesmas preferências. Os frutos de pupunha de Fonte Boa, usados no programa de fomento mencionado, são de cor vermelha, de tamanho médio a grande $(47 \pm 14 \mathrm{~g}$; até $75 \mathrm{~g})$ e secos (67,7 $\pm 10,4 \%$ amido vs $8,8 \pm 6,1 \%$ óleo no peso seco; Clement et al., 1998). A implicação clara é que futuros programas de pesquisa e fomento deveriam concentrar-se em frutos com maior demanda, como os de Coari, por exemplo ( $32 \pm 9 \mathrm{~g}$, até $50 \mathrm{~g} ; 54,5 \pm 13,8 \%$ amido vs $21,0 \pm 11,6 \%$ óleo; Clement et al., 1998). Atender a essas demandas num programa de melhoramento será difícil, pois alguns pares de caracteres preferidos possuem correlações negativas. No entanto, a mensagem mais importante é que é essencial entender melhor o consumidor de pupunha, quantificando suas preferências com mais eficiência, bem como o tamanho e comportamento dos diferentes segmentos deste mercado.

\section{AGRADECIMENTOS}

Os autores agradecem ao M.Sc. Johannes van Leeuwen pelas sugestões que melhoraram o manuscrito, e à Sra. Rosa Clement e um revisor anônimo pela revisão da linguagem.

\section{REFERÊNCIASBIBLIOGRÁFICAS}

CLEMENT, C.R. Descriptores mínimos para el pejibaye (Bactris gasipaes H.B.K.) y sus implicaciones filogenéticas, 1986. 216f. Dissertação (Mestrado em Biologia), Escuela de Biologia, Universidad de Costa Rica, San José, Costa Rica, 1986.

CLEMENT, C.R. 1492 and the loss of Amazonian crop genetic resources. I. The relation between domestication and human population decline. Economic Botany, Lawrence, KA, v.53, n.2, p.188-202, 1999.

CLEMENT, C.R. Pupunha (Bactris gasipaes Kunth, Palmae). Jaboticabal: Fundep, 2000. 48p. (Série Frutas Nativas, 8.)

CLEMENT, C.R.; ARKCOLL, D.B. The pejibaye (Bactris gasipaes H.B.K., Palmae) as an oil crop: potential and breeding strategy. Oleagineux, Paris, v.46, n.7, p.293-299, 1991.

CLEMENT, C.R.; AGUIAR, J.P.L.; ARKCOLL, D.B. Composição química do mesocarpo e do óleo de três populações de pupunha (Bactris gasipaes) do Rio Solimões, Amazonas, Brasil. Revista Brasileira de Fruticultura, Cruz das Almas, v.20, n.1, p.115-118, 1998.

MORA URPÍ, J.; WEBER, J.C.; CLEMENT, C.R. Peach palm. Bactris gasipaes Kunth. Promoting the conservation and use of underutilized and neglected crops, 20. Gatersleben: Institute of Plant Genetics and Crop Plant Research - IPK / Roma: International Plant Genetic Resources Institute - IPGRI, 1997. 83p.

MOREIRA GOMES, J.B.; CLEMENT, C.R.; FERREIRA, S.A.N; FONSECA, C.E.L. Variação fenotípica de pupunha (Bactris gasipaes H.B.K.) selecionada da população de Fonte Boa-AM. I. Análise univariada. In: CONGRESSO BRASILEIRO DE FRUTICULTURA, 9., 1987, Campinas. Anais... Campinas: Sociedade Brasileira de Fruticultura, 1987.p.679_684. 